\title{
Economic Analysis of Bio-Diesel for Agriculture Purpose of Indonesian Farm
}

Muhammad Bismadver Budiman ${ }^{1}$, Karsten Wehner ${ }^{2}$, Steffen Loest ${ }^{3}$

(Received: 08 August 2019 / Revised: 04 September 2019 / Accepted: 28 September 2019)

\begin{abstract}
Indonesia's Agency for the Assessment and Application of Technology (BPPT), if present trends in energy usage continue unaltered, transport fuel consumption in Indonesia will increase on average almost $5 \%$ per year through 2050 . Currently, liquid fossil fuel accounts for around $35 \%$ of Indonesia's energy demand across all sectors. From various renewable energy and possible alternative fuels to replace the consumption of fossil fuels, biodiesel is projected to have potential to be developed regarding to the simple production process and affordable feed stocks. Biodiesel, as diesel engine fuel alternative, receives more attention among many feasible options. Biodiesel as one of the renewable energies, biodegradable and nontoxic fuel is expected to be one of the solutions. With the affordable feed stocks that can be obtained from various organic source like vegetable oils or animal fats and also the simple production, From the discussion of this research, the economic feasibility, necessary equipment and the time of storage of the biodiesel will be analyzed for biodiesel production plant including investment cost of making the biodiesel production plant by calculating the capital cost and the operational cost of a 5000-ton annual capacity of biodiesel. The purpose of this study is to analyze the investment of the biodiesel production facility by using a feasibility study method by using four parameters of economic feasibility study namely Net Present Value (NPV), Internal Rate of Return (IRR), Payback Period (PP), and the Profitability Index (PI) for assessing the Investment. Th result obtained is that the biodiesel production facility with the annual production of 5000 ton of biodiesel is feasible
\end{abstract}

Keywords - agriculture, biodiesel, investment, renewable energies.

\section{INTRODUCTION}

$\mathrm{T}_{\mathrm{t}}$ he consumption of energy such as fossil fuels and petroleum products will always be increasing alongside with the population growth and increasing use of transportation and also other Sector which are using fuels as their main source of power. Also, the preservations of this non-renewable energy are depleting and projected to be running out in the upcoming years. It is required to find the replacement of this fossil fuel or known as alternative fuel to be used in generating power. Biodiesel fuel is an alternative renewable fuel for diesel fuel that are produced from different kinds of vegetable oils. As a renewable fuel, biodiesel can be used in diesel engines without significant modification. However, the performance, emission and combustion characteristic will be different for the same biodiesel used in different types of engine, the advantages of bio-diesels as diesel fuel are the minimal sulfur and aromatic content and higher flash point, lubricity, cetane number, biodegradability and non-toxicity. On the other hand, their disadvantages include the higher viscosity and pour point and the lower calorific value and volatility. Furthermore, their oxidation stability is lower, they are hygroscopic, and as solvents may cause corrosion in various engine components. Moreover, it is generally

Muhammad Bismadver Budiman, Departement of Maritime Sains and Engineering, Wismar University, Wismar, Germany. E-mail: bismadverb@gmail.com

Karsten Wehner, Departement of Maritime Sains and Engineering, Wismar University, Wismar, Germany. E-mail: karsten.wehner@hswismar.de

Steffen Loest, Departement of Maritime Sains and Engineering, Wismar University, Wismar, Germany. E-mail: steffen.loest@hswismar.de accepted that blends of diesel fuel, with up to $20 \%$ biodiesels can be used in existing diesel engines without modifications [2].

Biodiesel can be produced from several variety of feedstock. Commonly the production of the biodiesel is using grease, vegetable-oils, or animal fats for its raw material. These raw materials have the chemical structure is of fatty acid alkyl esters that are the main source for producing biodiesel. Biodiesel is produced by the transesterification process of oils with short chain alcohols or by the esterification of fatty acids [1]. The advantages of bio-diesels as diesel fuel are the minimal sulfur and aromatic content and higher flash point, lubricity, cetane number, biodegradability and nontoxicity. The wide range of available variety of the feedstocks for the production of biodiesel represents one of the most significant factors of producing biodiesel. For that the available feedstock should fulfill two main requirements, low production costs and large production scale. The availability and the quality of feedstock for producing biodiesel depends on several factors, the geographical locations, soil condition, climate and agricultural practice. Over than 350-oil bearing crops have been identified as potential sources for producing biodiesel. However, there are only several plant that are considered to be viable feedstock for the commercial production of biodiesel such as, Palm, Jathropha, rapeseed, sunflower, soybean, safflower and peanut oils. In general, biodiesel feedstock can be categorized into four main categories which are Edible Oil, Non-edible oil, Animal Fats, and Another source [9].

Edible oils are considered as the first-generation feedstock for biodiesel production it is due to reason of that these crops are the first crops to be used for biodiesel production. Resources such as soybeans, palm oil, sunflower, safflower, rapeseed, coconut and peanut are considered as the first generation of biodiesel feedstock. The plantations of the first generation of 
biodiesel feedstock have been established in many countries around the world with great biodiesel potential. This includes Malaysia, USA and Germany. More than $95 \%$ of the world biodiesel is produced from edible oils such as rapeseed $(84 \%)$, sunflower oil $(13 \%)$, palm oil $(1 \%)$, soybean oil and others $(2 \%)$. But the use of these crops raises many concerns such as food versus fuel crisis and major environmental problems such as serious destruction of vital soil resources, deforestation and usage of much of the available land. Moreover, in the last 10 years the prices of vegetable oil plants have increased dramatically which will affect the economic viability of biodiesel industry [8].

For overcoming these problems, one of the possible solutions is to reduce the utilization of the edible oil for biodiesel production is by exploiting non-edible oils. Non-edible oil resources are gaining worldwide attention because their availability. These Non-Edible feedstocks can be found in many parts of the world especially wastelands that are not suitable for food crops that will eliminate competition for food, reducing deforestation rate, more environmentally friendly, produce useful byproducts and they are very economical comparable to edible oils. The main sources for biodiesel production from non-edible oils are jatropha or ratanjyote or seemaikattamankku (Jatropha curcas), karanja or honge (Pongamia pinnata), Aleurites moluccana, Pachira glabra nagchampa (Calophyllum inophyllum), rubber seed tree (Hevca brasiliensis), Desert date (Balanites aegyptiaca), Croton megalocarpus, Rice bran, Seamango (Cerbera odollam), Terminalia belerica,neem(Azadirachta indica), Koroch seed oil (Pongamia glabra vent.), mahua (Madhuca indica and Madhuca longifolia), Tobacco seed (Nicotiana tabacum L.), Chinese tallow, silk cotton tree (Ceiba pentandra), jojoba (Simmondsia chinensis), babassu tree and Euphorbia tirucalli. Non-edible oil is considered as the second generation of biodiesel feedstocks. Another feedstock that are also considered as the second-generation feedstock are animal fat waste oil and grease. Usually these feedstocks are disposed. The use of these types of feedstock eliminates the need to dispose them. However, it has been reported that second generation feedstocks may not be plentiful enough to satisfy the global energy demand. Furthermore, for many types of animal fats the transesterification process is difficult because they contain high amount of saturated fatty acids. In case of waste cooking oil, collection infrastructure and logistics could be hurdle as the sources are generally scattered. [9].

As the Second Largest Biodiesel Producing Countries, Indonesia has a great potential in case of the development of the Biodiesel, Especially in Agriculture sector. Indonesia is very rich in natural resources which can be utilized as a biodiesel raw material. The development of biodiesel requires vegetable oil raw materials as the feedstock that can produced from plants containing fatty acids such as oil palm (Crude Palm Oil /

\section{B. Cash Flow}

Cash Flow is the flow of cash in a company inside certain period that shows the amount of money that goes into the company and the types of income and the
CPO), Jatropha (Jatropha Curcas), soybean, coconut, soursop and kapok.

Agriculture Sector is a very important sector which they are not only playing the role of the producer of production of the Biodiesel, but also forms as a potential user in which it uses the Biodiesel Product from the feedstock that are produced by the farmer itself to replace the needs to use diesel fuel. This way the it may be possible to reduce the cost for diesel fuel consumption by totally replacing the diesel fuel with the produced biodiesel. Therefore, in this study the economic feasibility for biodiesel production plant in specific area including investment cost of making the biodiesel production plant by calculating the capital cost and the operational cost so that it can be determined whether the biodiesel it is feasible or not. The yearly consumption of the biodiesel for a specific area will be calculated, also the economical calculation to allow the most costeffective implementation as possible.

\section{METHOD}

\section{A. Biodiesel Characteristics}

Diesel engines have different ignition, emission and injection characteristic; therefore, the use of biodiesel is restricted. The treatment of biodiesel is needed to make biodiesel usable for diesel engine [10]. The high viscosity, density of vegetable oil interferes with injection process and leads poor fuel atomization. The viscosity of fuels has important effects on fuel droplet formation, atomization, evaporation and fuel-air mixing process, thus influencing the exhaust emission and performance parameters of the engine [9].

Palm oil biodiesel has a better efficient than biodiesel produced from another vegetable oils. The lower of energy content of biodiesel make diesel engine consumed more fuel then regular diesel oil. The lowering of power can be to $5-10 \%$, it depends on type of biodiesel, engine speeds and loads [11]. Semin in 2018 has done research about performance biodiesel using cotton seed oil with mixture B20 and B30 with the result performance increase compared to regular diesel oil. However, the consumption is higher [17]. Preheating process is needed for the vegetable oils. It will make viscosity reduce and making the biodiesel more likely to petroleum diesel. By reducing Viscosity make the biodiesel suitable for diesel engine because high viscosity causing fuel flow and ignition problems [12].

The bio diesel is B20 which contain $80 \%$ diesel fuel and $20 \%$ CPO. The more contain of CPO then makes the density and the kinematic viscosity of the biodiesel getting high. High viscosity will make results in reduced flow rates for equal injection pressure and reduced atomization. In other condition, fuels with high viscosity has larger droplets on injection which can make poor combustion, increased exhaust smoke and emissions

amount of money that comes out and the types of costs incurred. The cash flow report is compiled to show changes in cash for one certain period and provide reasons for changes in the whole flow of the cash by 
showing the source of cash and the usage of the cash. When analyzing for future estimated cash flow, uncertainty is there. As a result, the estimated calculation can deviate far from reality. This uncertainty can cause a reduction in the ability for the development of the project to operate for generate profits for the company. To determine the feasibility of an investment or project terms of financial aspects, it can be measured by assessing the value of several factors. Every assessment has standard value for similar business by comparing with the average industry or predetermined target. The criteria commonly used for determining the feasibility of a business of investment:

\section{1) Net Present Value (NPV)}

NPV is a net financial assessment that is in the company after reduced by the other cost so that the value of the increase or shortage of the financial in the company can be used as a reference for judging the worthiness of the company's finance. In other words, The assessment of NPV is the net flow of the company's financial so that it can be interpreted as financial analysis which is used to determine the worthiness of the business or investment by seeing through the present value of the net cashflow that are received by the company compared to the value from the investment capital done by the company. The NPV can be determined using the following formula [7].

$$
N P V=\sum_{t=1}^{n} \frac{B t-C t}{(1+i)^{t}}
$$

\section{2) Internal Rate of Return (IRR)}

IRR (Internal Rate of Return) is an investment calculation method that is done by calculating the interest rates which equates the present value of investment with the future present value of net cash receipt. The IRR can also be used as the value of the discount rate which makes the NPV of the projects equal to zero. It can also be considered as the rate of return on net investment from a project, as long as every net benefit is obtained automatically reinvested by the following year with the same level of profit and the given interest.[7]

$$
I R R=\dot{i}_{1}+\left[\frac{N P V_{1}}{N P V_{1}-N P V_{2}}\right]\left(\dot{i}_{2}-\dot{i}_{1}\right)
$$

\section{3) Payback Period}

Payback period is a period of time to indicate how long the return of an investment or project will be., by paying attention to assessment techniques for a certain period of time. Payback Period is the time needed in units of year to return the investment that are invested based on the cash inflow generated by the investment or project. Payback Period (PP) shows a comparison between the initial investment and the annual cash flow. Payback
Period (PP) can be determined using the following formula:

$$
\text { Payback Period }=\dot{i} / \pi \times 1 \text { year }
$$

\section{4) Profitability Index}

Profitability index (PI) or benefit cost ratio is a comparison between the present value of future cash inflows with the value of the investment. For the Profitability Index is equal to or greater than one $\mathrm{PI} \geq 1$, then the project is to be accepted. Generally, the NPV and PI methods are used to assess an investment proposal, the results will always be consistent. In other words, if the NPV is acceptable than the Profitability index is acceptable too and vice versa[10], for calculating the Profitability Index (PI), the NPV has to be determined first and in several other cases, which after determining the Profitability index (PI) decision could not be made before being returned to the NPV method. This can be concluded that Profitability Index (PI) is a method of predicting the feasibility of a project by comparing the value of net profitability with the investment, with eligibility criteria if the Profitability Index is greater than one $P I \geq 1$, then the investment is acceptable, whereas if the Profitability index is smaller than one $\mathrm{PI} \leq 1$, the investment is not acceptable.

\section{5) Net Benefit Cost (Net B/C)}

Net Benefit Cost is a comparison of benefits and net cost of a project. It is the comparison between the total value of benefits in the year which the benefits are positive and the total present value of the benefits net in years where they are negative (losses)[7]. The method for calculating Net Benefit cost use the formula below

$$
\text { Net } B / C=\frac{N P V_{B}-C \text { positive }}{N P V_{B}-C_{\text {nequtive }}}
$$

\section{6) Break Event Point (BEP)}

Break event point is a situation where the level of production or the amount of income are equals to the amount of expenditure on a project, sot that in these circumstances the project does not gain benefit or not losses [7]. Breakeven point can found using the following formula.

$$
B E P(\text { Rupiah })=\left[\frac{\text { Fixed cost }}{1-\frac{\text { Total Variable Cost }}{\text { Sales Revenue }}}\right]
$$

$$
E P(\text { Unit })=\left[\frac{B E P(\text { Rupiah })}{\text { Selding Price of Unit }}\right]
$$

\section{RESULTS AND DISCUSSION}

\section{A. Data Collection}

For the first decision for making the biodiesel production facility is the capacity of the production which will provides and cover the consumption of the 
area. For that reason, it is necessary to look for the consumption for that specific area or province. Fuel consumption in the province of Nusa Tenggara Barat have increased each year. The consumption of the premium type and the diesel fuel increased when compared to the previous year, with the consumption of the premium and the diesel fuel for Nusa Tenggara Province in 2016 is 203,998.37 Kiloliter.

According to current available data of the diesel consumption for Nusa Tenggara Barat region, with the total of 203,988.37 Kiloliters. Another parameter that must be taken into consideration are the availability of the raw material or feedstock that will be produced into biodiesel. Nusa Tenggara Barat is well known as one of the most Soybean Producer province in Indonesia with the productivity of 97.200 ton of soybean in 2014 and in the next year the production has increase into 115.000 ton in 2015.

Summarizing from the parameters above, the construction of a 5000-ton annual capacity of the biodiesel plant may be reasonable and feasible to be invested since it results in a moderate investment for the farmer to be investing in. Furthermore, the selection of the capacity for the current research is convenient in case of the capital investment and a reasonable and feasible operational cost. In this case of research, the design and cost analysis that of a biodiesel production with an annual capacity of 5000-tons.
The plant design is modelled based on two sequential transesterification reactions. Biodiesel is the product obtained from the chemical reaction of vegetable oil or animal fat with an alcohol to produce fatty acid alkyl esters. In the reaction, a catalyst is required. In a biodiesel production process, glycerol can be produced as a co-product. The approximate proportions for the reaction from making the biodiesel product are:

$1000 \mathrm{Kg}$ of Oil $+110 \mathrm{Kg}$ of Methanol $\rightarrow 1000 \mathrm{Kg}$ of Biodiesel $+110 \mathrm{Kg}$ of Glycerol

For the purpose of the reaction catalyst use usually requires a quantity of $1.5 \%$ of the oil quantity that will be processed. Based on several researches the production for a ton of biodiesel required approximately $60 \mathrm{kWh}$ of input electricity. For a biodiesel plant operation Natural gas is often used to generate steam for the evaporation and distillation process. For a ton of biodiesel produced an average of $440 \mathrm{kWh}$ of Natural gas supply is required. For water requirements, biodiesel plant used approximately 1.28 tons of water for each ton of biodiesel. the evaporation and distillation process. For a ton of biodiesel produced an average of $440 \mathrm{kWh}$ of Natural gas supply is required. For water requirements, biodiesel plant used approximately 1.28 tons of water for each ton of biodiesel.

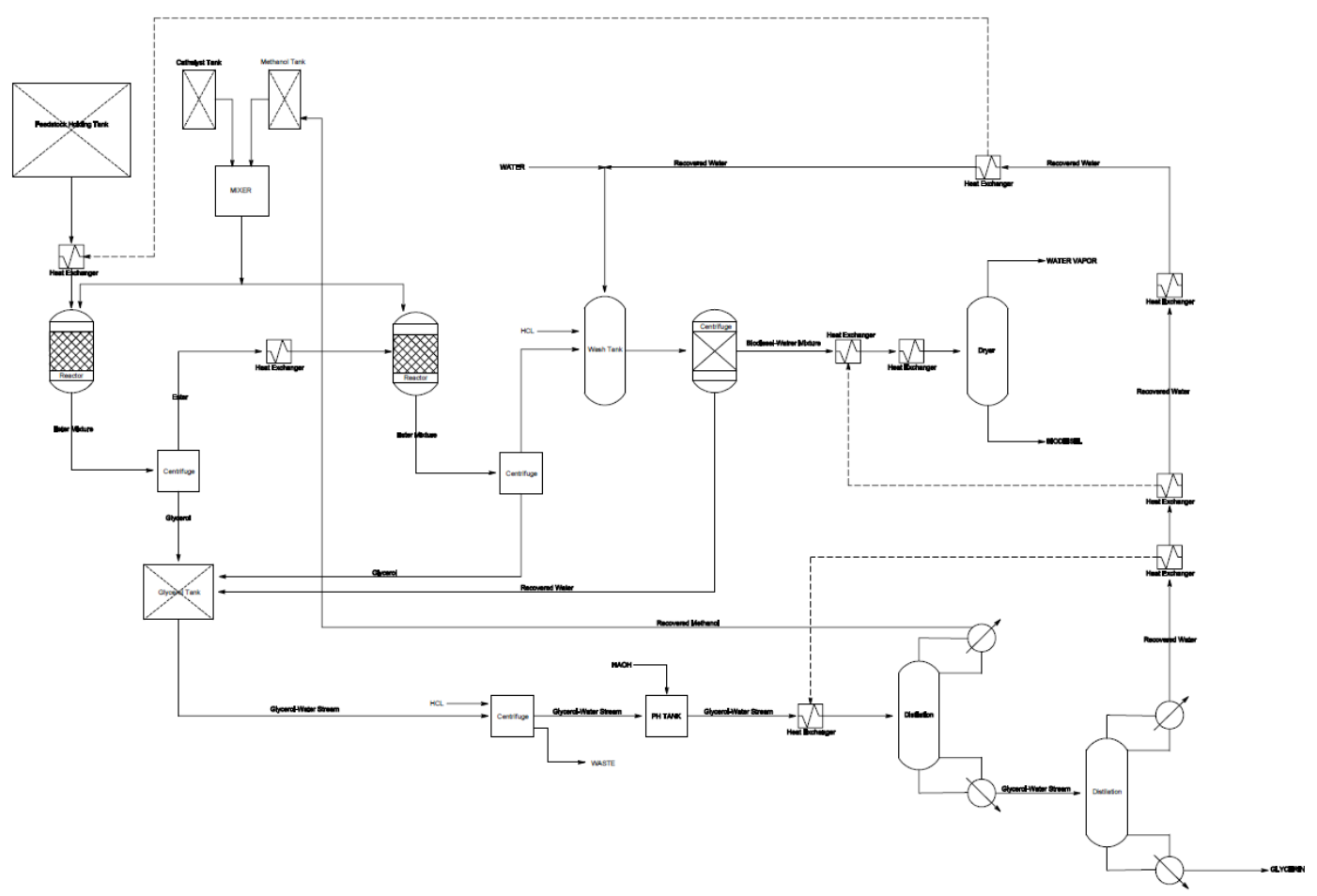

Figure. 1. Process flow Diagram of Biodiesel production model

The production of the biodiesel consisted of three processing sections:

1. Transesterification process, in which the vegetable oil is subject to chemical transesterification in order to produce the fatty acid methyl in which is the biodiesel product and the co-product of glycerol.

2. Purification process, in which the methyl esters produced from the transesterification are refined to meet the standard specification. 


\section{Glycerol Recovery process.}

\section{B. Transesterification Stage}

Transesterification begins the mix of the oil which uses catalyst to achieve continuous reaction in a reactor. Following the continuous reaction in the reactor, a centrifugation of the reaction is employed to separate between the methyl ester product and glycerol-rich product which is later sent to the glycerol recovery unit for the glycerol recovery process. The methyl ester which still contains unreacted methanol, vegetable oil, and catalyst is then sent into a second reactor. In this reactor the crude ester product is removed from the reactor at a rate equal to that of reagent addition.

The Mixture of the Methyl esters, Glycerol, catalyst and unreacted substrates exiting the second reactor is fed to a continuous centrifuge which again separate the methyl ester product with the glycerol rich product. Then the Impure Methyl ester product goes to the biodiesel refining process for dehydration and purification.

\section{Biodiesel Purification Stage}

The Impure or crude methyl ester that which already been separated from the glycerol product is washed with water to neutralize the catalyst and convert any soaps to free fatty acids to reduce their emulsifying tendencies. Then the biodiesel product is entering a centrifugal pump to separate the biodiesel product from the aqueous phase. Before the crude methyl ester (biodiesel) are stored in the Biodiesel Tank, it goes through a vacuum dryer. This is done to lower the content of water that may still be in the biodiesel

\section{Glycerol Recovery Stage}

The amount of Glycerol-high product that was generated from the Transesterification and the Biodiesel Purification Process are collected in a Glycerol collecting Tank. The collected mixtures are then treated with hydrochloric acid $(\mathrm{HCl})$ to form free acids, allowing removal by Centrifugal Pump. The Glycerol that goes through the Centrifugal pump is then neutralized by using caustic soda in PH adjustment tank. The neutralized stream of Glycerol then goes into Distillation process to recover methanol to be used into the transesterification process. After it goes through a distillation process to recover methanol content, it goes through a final distillation process to reduce the water content from the Glycerol mixture.

The recovered water during the Biodiesel Purification Process and Glycerol Distillation can be used and are recycled back into Biodiesel Purification process for the washing of the Methyl Ester mixture purpose. Heat exchangers included to recover the heat from each condensation.

The model of the Process flow diagram in Figure 1 is meant to be used for assessing the effects on estimated biodiesel production costs of changes in feedstock and glycerol prices, chemical or process technology that are used, or in equipment specified for the facility. The model is flexible and meant to be use as a tool in estimating the capital cost and the operating cost of the facility. Based on Figure 4.1 of the biodiesel production processes the Equipment necessary for Biodiesel Production Plant for each of the processing sections are shown in Table 1.

\section{E. Economic Analysis}

Based on the necessary equipment needed that are shown in Table 1 The capital cost can be summarized. The model is flexible, and is meant for use in assessing the effects on estimated biodiesel production costs of changes in feedstock and glycerol prices, in chemical or process technology employed, or in equipment specified for the facility. Based on the process flow diagram shown in Fig. 1, capital and production costs were calculated. Capital costs are summarized in Table 2. The cost parameters of the biodiesel production can be split into the annual biodiesel production cost which include the oil extraction and the biodiesel production, and the Investment costs. The Investment costs can be characterized as the capital costs for the costs of the equipment necessary for the production, the land acquisition assets and the associated infrastructure labor costs. As for the Annual Biodiesel production costs, it is divided into two categories which are the Annual Oil Extraction and the Annual Biodiesel Production.

This analysis calculates a final biodiesel production cost of US\$ 55.901.36. Raw materials costs constitute the greatest component of overall production costs, and of these the cost of the soy oil feedstock is the biggest contributing factor, itself constituting $76 \%$ of the overall production cost.

The total cost of the biodiesel production plant, including the investment cost and annual cost are shown in Table 3 and Table 4 . The analysis calculated the final biodiesel production cost of $\$ 1.14 / \mathrm{L}$. Raw materials constitute the greatest cost of overall production costs which is $83 \%$, and of those the cost of the Feedstock oil in this case the Soybean Oil is the largest contribute factor, almost $77 \%$ of the overall production cost. The large contribution of feedstock cost to the cost of biodiesel highlight the potential value of low-cost vegetable oil alternatives to the improvement of the biodiesel plant economic viability. Concerning the Investment cost the analysis resulted in the total cost of the investment of $\$ 1,970,341$. The Land and Infrastructure cost constitute the biggest cost of $54 \%$ of the total investment cost. Based on the total capital cost that is $\$ 1,970,34$, the loan capital with the proportion of 70:30 (\%).

Accounting the selling price of the meal produced from the oil extraction process it was worth $\$ 0.34 /$ Liter of meal and the selling of the biodiesel product and the glycerin co-product worth $\$ 0.51 /$ Liter and $0.60 /$ Liter respectively. Taking the market price of biodiesel is $\$ 0.51 /$ Liter, the net return from producing biodiesel was $\$ 0.31 /$ Liter of biodiesel. The net return from biodiesel production is presented on Table 5 . 
International Journal of Marine Engineering Innovation and Research, Vol. 4(2), Sept. 2019. 96-103 (pISSN: 2541-5972, eISSN: 2548-1479)

TABLE 1.

BIODIESEL PLANT PRODUCTION EQUIPMENT

\begin{tabular}{cll}
\hline No. & Item & \multicolumn{1}{c}{ Description } \\
\hline 1 & Reactor Pre-heater & Tranesterification Equipment \\
2 & Biodiesel Reactor & Tranesterification Equipment \\
3 & Centrifuge & Tranesterification Equipment \\
4 & Methanol Storage Tank & Tranesterification Equipment \\
5 & Catalyst Storage Tank & Tranesterification Equipment \\
6 & Methanol/ Catalyst Mixer & Tranesterification Equipment \\
7 & Biodiesel Wash Tank & Biodiesel Purification Equipment \\
8 & Centrifuge & Biodiesel Purification Equipment \\
9 & Pre-heater & Biodiesel Purification Equipment \\
10 & Heater & Biodiesel Purification Equipment \\
11 & Vacumm Dryer & Biodiesel Purification Equipment \\
12 & GlycerolCollection Tank & Glycerol Recovery Equipment \\
13 & Glycerol Distillation System & Glycerol Recovery Equipment \\
14 & Methanol Distillation System & Glycerol Recovery Equipment \\
15 & PH Adjustment Tank & Glycerol Recovery Equipment \\
16 & Centrifuge & Glycerol Recovery Equipment \\
17 & Fatty Acid Storage Tank & Glycerol Recovery Equipment \\
18 & NAOH mix Feeder & Glycerol Recovery Equipment
\end{tabular}

TABLE 2.

CAPITAL COST

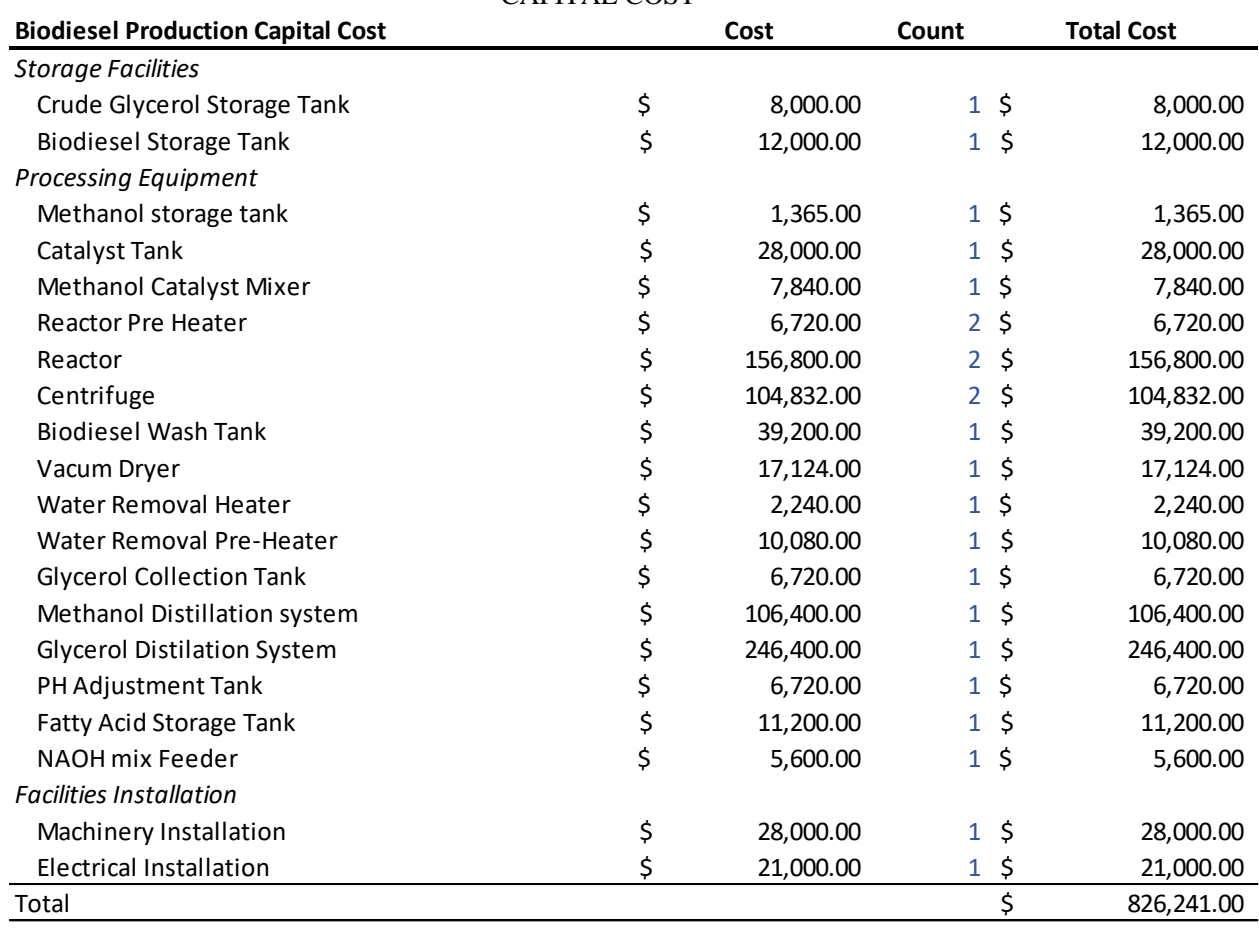


TABLE 3.

OIL EXTRACTION INVESTMENT COST

\begin{tabular}{|c|c|c|c|c|c|}
\hline Item & Cost & & Count & Unit & Total Cost \\
\hline $\begin{array}{l}\text { Raw Material } \\
\text { Feedstocks }\end{array}$ & $\$ 0.00$ & /ton & 55 & $\$$ & - \\
\hline $\begin{array}{l}\text { Utilities } \\
\text { Electricity }\end{array}$ & $\$ 0.10$ & & 1451.06 & $\$$ & 140.17 \\
\hline Labor & $\$ 245.00$ & /person & 1 & $\$$ & 245.00 \\
\hline Administration & $\$ 245.00$ & /person & 1 & $\$$ & 245.00 \\
\hline Production & $\$ 245.00$ & /person & 1 & $\$$ & 245.00 \\
\hline Maintenance & $\$ 245.00$ & /person & 1 & $\$$ & 245.00 \\
\hline Storage & $\$ 245.00$ & /person & 1 & & \\
\hline $\begin{array}{l}\text { Maintenance } \\
\text { Maintenance Supplies }\end{array}$ & $\$ 3,490.00$ & & & $\$$ & $3,490.00$ \\
\hline
\end{tabular}

TABLE 4.

ANNUAL OIL EXTRACTION COST

\begin{tabular}{llllll}
\hline Item & Cost & & Count & Unit & Total Cost \\
\hline Raw Material & & & & & \\
Soybean oil & $\$ 736.03$ & /ton & 961.0 & $\$$ & $707,326.93$ \\
Methanol & $\$ 430.00$ & /ton & 249.9 & $\$$ & $107,440.12$ \\
Catalyst & $\$ 2.07$ & /ton & 1270.2 & $\$$ & $2,631.77$ \\
$\begin{array}{l}\text { Hydrochloric Acid } \\
\text { Sodium Hydroxide }\end{array}$ & $\$ 196.00$ & /ton & 1 & $\$$ & 196 \\
Utilities & $\$ 441.00$ & /ton & 1 & $\$$ & 441.00 \\
Electricity & $\$ 0.10$ & /kWh & 57660.17 & $\$$ & $5,569.97$ \\
Natural Gas & $\$ 0.05$ & /kWh & 422841.25 & $\$$ & $20,837.62$ \\
Water & $\$ 0.25$ & /ton & 1230.08 & $\$$ & 301.37 \\
Labor & & & & & \\
Administration & $\$ 218.47$ & /person & 1 & $\$$ & 218.47 \\
$\begin{array}{l}\text { Production } \\
\text { Maintenance }\end{array}$ & $\$ 218.47$ & /person & 1 & $\$$ & 218.47 \\
Storage & $\$ 218.47$ & /person & 1 & $\$$ & 218.47 \\
$\begin{array}{l}\text { Maintenance } \\
\text { Maintenance Supplies }\end{array}$ & $\$ 218.47$ & /person & 1 & $\$$ & 218.47 \\
\hline & & & & & \\
\hline
\end{tabular}

TABLE 5 .

NET RETURN COST

\begin{tabular}{lcl} 
Category & Cost & \\
\hline Biodiesel Revenue (/L) & $\$$ & 0.51 \\
Meal Revenue & $\$$ & 0.34 \\
Glycerin Revenue (/L) & $\$$ & 0.60 \\
Total Revenue (/L) & $\$$ & 1.45 \\
Total Cost (/L) & $\$$ & 1.14 \\
\hline Net Return (/L) & $\mathbf{\$}$ & $\mathbf{0 . 3 1}$ \\
\hline
\end{tabular}

\section{CONCLUSSION}

Based on the analysis and the discussion that has been done, the conclusions are

1) The necessary Equipment for Biodiesel Production facility is based on the three stages of the production. And those stages include the Transesterification stage, the Biodiesel purification stage, and the glycerol recovery stage.

2) The maximum time of storing the biodiesel can be predicted by knowing the acidity value. The approach can be made by using the formula $y=0.0012 x^{\wedge} 2-0.0052 x+0.0609$ to predict the maximum storage time of biodiesel. By using the following formulas, the maximum time of storage for biodiesel may not be exceed 21 weeks of storage.
3) Raw Materials cost constitute the greatest cost of the overall production cost with $83 \%$ of the total production and the $73 \%$ are contributed from the cost of the soybean oil.

4) The contribution of the feedstock cost in this case the soybean oil to the overall cost shows the importance of a low-cost feedstock oil for improving the economic viability of the plant.

5) The loan period can be extended if more profits would be achieved. That way, once the biodiesel production facility is operating it could bring profits. However, the loan interest should also be noted. In this case choosing the smallest loan interest among domestic banks, both state-owned banks and private banks.

6) The economic feasibility study of the biodiesel production has a total cost of investment of $\$$ ,970,341. With the Net present value (NPV) 
$\$ 2,095,530.29$; Internal rate of Return (IRR) of $25 \%$, the payback period (PP) of 2.37 year; and the Profitability index (PI) of 4.0.

7) Based on the financial projections that has been carried out, with the estimation that has been fulfilled, the project to make a biodiesel production facility provides a positive contribution so that it is feasible to be implemented

\section{Acknowledgements}

Containing a thank you to those who deserve (donors/sponsors), materials contributor, and research facilities.

\section{REFERENCES}

[1] P. T. Vasudevan and M. Briggs, "Biodiesel Production-current state of the art and challenges," J. Ind Microbiol Biotechnol, pp. 421430, 2008.

[2] A. Sathiyagnanam and C. Saravan, "Experimental Studies on the combustion Characteristics and Performance of a Direct Injection Engine fueled with Biodiesel/Diesel Blend with SCR," in World Congress on Engineering, 2011.

[3] M. Saifuddin and A. Boyce, "Biodiesel Production from fish waste and Evaluation of Engine Performance," Sains Malaysiana, pp. 1771-1778, 2017

[4] P. Pavan, B. K. Venkanna, B. Mudhol and K. Pavan, "Performance characteristic of diret injection diesel engine running on mackerel fish oilbiodiesel/ diesel fuel blend," International Journal of Scientific\& Engineering Research, Volume 6,Issue 1, 2015.

[5] K. Kara, F. Ouanji, E. M. Lotfi, M. E. Mahi, M. Kacimi and M. Ziyad, "Biodiesel production from waste fish oil with high fre fatty acid content from Morocan fish-Processing Industries," Egyptian Journal of Petroleum, 2017.

[6] M. Jakeria, M. Fazal and A. Haseeb, "Influence of different factors on the stability of biodiesel," A review ,Renewable andSustainable Energy Reviews, pp. 154-163, 2014.

[7] BI, "Pola Pembiayaan Usaha Kecil," Bank Indonesia, Batam, 2014.

[8] M. Balat and H. Balat, Progress in Biodiesel processing, 2010.

[9] M. Ahmad, A. M. Khan, M. Zafar and S. Sultana, Biodiesel from Non Edible oil Seeds: a Renewable Source of Bioenergy, Islamabad, 2011. 